\title{
Do authors need guidance?
}

The wish that news of discovery should quickly reach the public that pays for it should be more often tempered by deliberation. Prior publication is, by definition, premature.

IT is well-known that there is nothing so boring as when journals like this write about themselves or about others that resemble them, but it may not yet be time to switch to another page. What follows is about the guidance given by journals other than this to researchers who are would-be authors. That guidance, to say the best of it, is confusing, but no more so than in the matter of the propriety of prior disclosure. The occasion for what may seem too much like a homily is the appearence in Physical Review Letters, and also in other journals from the US Institute of Physics, of what may seem to be an allembracing, or even over-embracing, catalogue of dos, don'ts and maybes.

$P R L$, as it is known, is among the most authoritarian of all journals. It is especially dogmatic on the space that contributions are allowed to fill. At regular intervals, there is published a standard recipe by which contributors can calculate for themselves how many keystrokes by their typist's fingers will fill up the maximum of four pages of text. Headings, of course, count extra, references must be tallied separately and there is a kind of algorithm for working out the space occupied by diagrams. It is remarkable how well contributors respond: almost all published articles turn the third page, but the upper limit is evidently enforced.

$P R L$ is also among the most authoritative of journals, which attribute derives from its creator and first editor, the late Sam Goudschmidt (with Uhlenbeck, the premature discoverer in 1926 of electronspin). Goudschmidt's cleverness was to recognise that a few dedicated typists working with typewriters equipped with interchangeable fonts on golf-balls could come near to simulating typesetters' type, but could also send a contributor a simulation of his typeset proof more quickly than conventional journals. (The need to simulate has now, of course, disappeared.) Goudschmidt's personal concern for the integrity of what his journal published, matched only by Chandrasekar's care for the Astrophysical Journal, was naturally another important consideration.

As it happens, Goudschmidt during his life had only one consistent complaint against his authors - their evident liking for being published on the front page of the New York Times as well as in PRL. Yet in the 1960s, the habit seemed incorrigible: there was always an anti-proton or some other exotic particle whose dis- covery seemed that important. Goudschmidt's war against the practice of prior release was so effective that, even if science never disappeared for long from the front page of the New York Times, at least his contributors became well-versed in explanations of how their work had arrived there by accident.

How things have now changed. $P R L$ 's latest version of its authors' guide, bound in with its issue of $3 \mathrm{July}$, includes a statement on prior disclosure that will have even unshockable Sam Goudschmidt turning in his grave. The journals of the American Physical Society, the statement says, are just like other journals in requiring that authors should not previously have published what they have to say elsewhere. The explanation, the statement says, is that, "for decades", editors "have frowned on multiple publication". (Presumably, if they chose, they could stop frowning, and maybe some have stopped already.)

But there are naturally exceptions to every rule - abstracts prepared for meetings and later published, students' theses and even "abbreviated or preliminary" accounts of research appearing in conference proceedings. Authors are warned that it is their job to get permission for reproducing duplicated material from whoever may hold the copyright.

Curiously, $P R L$ does not on this occasion refer to the most abundant form of duplicate publication - the preprint business. Yet $P R L$ functions in many of the fields in which preprints are most common. In high-energy physics, for example, active researchers have been exchanging advance copies of what they plan to send to $P R L$ since long before the journal itself came into being, largely because there were then no journals rapid enough to accomodate their needs. But now that $P R L$ has been established as both rapid and catholic, instead of the preprint habit dying away, it has spread to other important fields of physics.

The explanation is straightforward. While a preprint may outwardly seem a means by which innocent researchers tell their competitors what they are about sooner than would otherwise be possible, they are also effective ways of ensuring that everybody knows who did what first. Informally, preprints and not publications determine the priority for discovery. But, sadly, preprints are innocent of referees' opinions and their consequences, tend to be laden with unwarranted speculations and are generally confusing. Nobody would now seriously suggest that they should be abolished, for the habit is too deeply engrained, but $P R L$ does not even raise the need that they, like students' theses, should be exempted from the interdiction of "multiple publication".

There is worse to come. $P R L$, on behalf of the American Institute of Physics, repeats its now familiar exceptions from the restraints of multiple publication the case in which news of scientific discoveries appear first in popular magazines - Time, Newsweek, Scientific American and Physics Today get special mention, but prior publication by "newspaper, television and radio" is not to be held a restraint of publication in one of the journals of the American Physical Society. The reason given is that publication of research should be "timely", especially because "much research is funded by public agencies".

The argument carries little weight. What there is consists of the expectation that fresh news of discovery is more immediate, and therefore more compelling, than news which has been filtered through the peer-review systems of the journals. And on the principle that there must be exceptions to any rule, only a true pedant could insist that news of the discovery of a moon for Neptune should be this week withheld from anybody once it is to hand or, released, should prejudice eventual publication. But there are serious drawbacks in the American Physical Society's encouragement of early popular publication of general news of discovery in science. What, for example, if the authors are afterwards found to be mistaken?

What this implies is that the American Physical Society should think hard about its policy of unrestrained prior release and then preferably abandon it. Even in cut-and-dried physics, there have been too many unsustained claims for most people's comfort. But the more serious misfortune of the present arrangements is that the chance that particular discoveries will command their fair share of the general public's attention depends too much on the doings of institution's public relations enterprises - and even those in universities are not above reproach. Sam Goudschmidt, being the first, may have been an unsystematic editor of $P R L$, but his instincts on this issue were correct.

John Maddox 